\title{
Vasoactive Intestinal Peptide and Noradrenaline Exert Long-Term Control on Glycogen Levels in Astrocytes: Blockade by Protein Synthesis Inhibition
}

\author{
Olivier Sorg and Pierre J. Magistretti \\ Institut de Physiologie, Université de Lausanne, CH-1005 Lausanne, Switzerland
}

\begin{abstract}
Vasoactive intestinal peptide (VIP) and noradrenaline (NA) have been previously shown to promote glycogenolysis in mouse cerebral cortex (Magistretti, 1990). This action, which is fully expressed within a few minutes, is exerted on astrocytes (Sorg and Magistretti, 1991). In the present article, we report a second, temporally delayed, action of VIP or NA in primary cultures of mouse cerebral cortical astrocytes; thus, following glycogenolysis, an induction of glycogen resynthesis is observed, resulting, within $9 \mathrm{hr}$, in glycogen levels that are 6-10 times higher than those measured before the application of either neurotransmitter. This effect of VIP or NA is concentration dependent and, for NA, is mediated by adrenergic receptors of the $\beta$ subtype. The continued presence of the neurotransmitter is not necessary for this longterm effect, since pulses as short as $1 \mathrm{~min}$ result in the doubling of glycogen levels $9 \mathrm{hr}$ later. The induction of glycogen resynthesis triggered by VIP or NA is dependent on protein synthesis, since both cycloheximide and actinomycin $D$ abolish it entirely. The ability to elicit glycogenolysis is not sufficient per se to trigger the induction of glycogen resynthesis. Thus, two glycogenolytic agents such as methoxamine, an $\alpha_{1}$-adrenergic agonist, and phorbol 12,13-dibutyrate, both acting via protein kinase $\mathrm{C}$ activation, are unable to induce glycogen resynthesis. This observation, taken together with the fact that dibutyryl-cAMP application also results in enhanced glycogen resynthesis, strongly suggests that the long-term effect of VIP or NA is mediated by the CAMP second-messenger pathway. These results indicate that the same neurotransmitter, for example, VIP or NA, can elicit two actions with different time courses: (1) glycogenolysis, occurring within minutes, and (2) glycogen resynthesis, fully expressed after several hours. The two actions are mechanistically coordinated since the long-term one, that is, glycogen resynthesis, ensures that sufficient substrate is available for the expression of the short-term effect, that is, glycogenolysis. These results also indicate that the glycogen content of astrocytes in primary culture, a condition in which neurons are absent, can increase considerably; a parallel could therefore be drawn with the marked
\end{abstract}

\footnotetext{
Received Apr. 24, 1992; revised July 6, 1992; accepted July 16, 1992.

We thank Dr Jean-Luc Martin for his comments and for helpful discussions. This work was supported by a grant from Fonds National Suisse de la Recherche Scientifique (31-26427.89) to P.J.M.

Correspondence should be addressed to Pierre J. Magistretti, M.D., Ph.D., Institut de Physiologie, Université de Lausanne, 7 rue du Bugnon, CH-1005 Lausanne, Switzerland.

Copyright (C) 1992 Society for Neuroscience $0270-6474 / 92 / 124923-09 \$ 05.00 / 0$
}

increases in brain glycogen content, particularly in astrocytes, that are observed in experimental neurodegeneration induced by brain trauma or $\mathrm{x}$-irradiation (Shimizu and $\mathrm{Ha}$ muro, 1958; Lundgren and Miquel, 1970). In both conditions, the increase in glycogen occurs in reactive astrocytes that have been partially or totally deprived of their neuronal environment.

The glycogen content of the rodent brain ranges between 20 and $60 \mathrm{nmol} / \mathrm{mg}$ protein, depending on the region (Passonneau and Lauderdale, 1974; Sagar et al., 1987). In the cerebral cortex, glycogen levels are approximately $30 \mathrm{nmol} / \mathrm{mg}$ protein (Sagar et al., 1987). Glycogen is localized in astrocytes, to such an extent that this cell type can be positively identified at the ultrastructural level by the presence of glycogen granules in the cytoplasm (Peters et al., 1991). This astrocytic glycogen pool is metabolically very active, as indicated by its rapid turnover rate (Watanabe and Passonneau, 1973; Ibrahim, 1975; Siesjö, 1978) and by the fact that it is under the control of multiple regulatory mechanisms (Magistretti, 1988). Thus, decreased synaptic activity, achieved for example by anesthesia (Nelson et al., 1968; Brunner et al., 1971; Passonneau et al., 1971), markedly increases the glycogen content of the brain, particularly in astrocytes (Phelps, 1972). Administration of the glutamine synthetase inhibitor methionine sulfoximine has similar effects (Phelps, 1975). Glycogen levels are also increased during slow-wave sleep (Karnovsky et al., 1983). Under normal conditions, glycogen is hardly visible at the light microscopic level using standard staining procedures (Shimizu and Hamuro, 1958). However, a common finding reported following lesions of the brain parenchyma either of traumatic origin, for example, stab wound (Shimizu and Hamuro, 1958; Hager et al., 1967; Haymaker et al., 1970; Watanabe and Passonneau, 1974; Al-Ali and Robinson, 1982) or by x-ray irradiation (Wolfe et al., 1962; Lundgren and Miquel, 1970), is a massive deposition of glycogen granules, predominantly in glial cells at the periphery of the lesioned area. These histochemical observations have been confirmed by biochemical measurements of glycogen levels following brain trauma, which indicate an early (i.e., within $10 \mathrm{~min}$ ) decrease followed by a delayed increase in glycogen after $2.5-24 \mathrm{hr}$ (Watanabe and Passonneau, 1974). Another neurodegenerative condition in which glycogen accumulations are observed, particularly in the cerebral cortex, is Alzheimer's disease (Mann et al., 1987). Brain glycogen levels are also under the tight control of numerous neurohumoral factors (Magistretti, 1988). Thus, the monoamines noradrenaline (NA), histamine, and serotonin (5-HT) (Quach et al., 1978, 1980, 1982), as well as adenosine and the peptide 


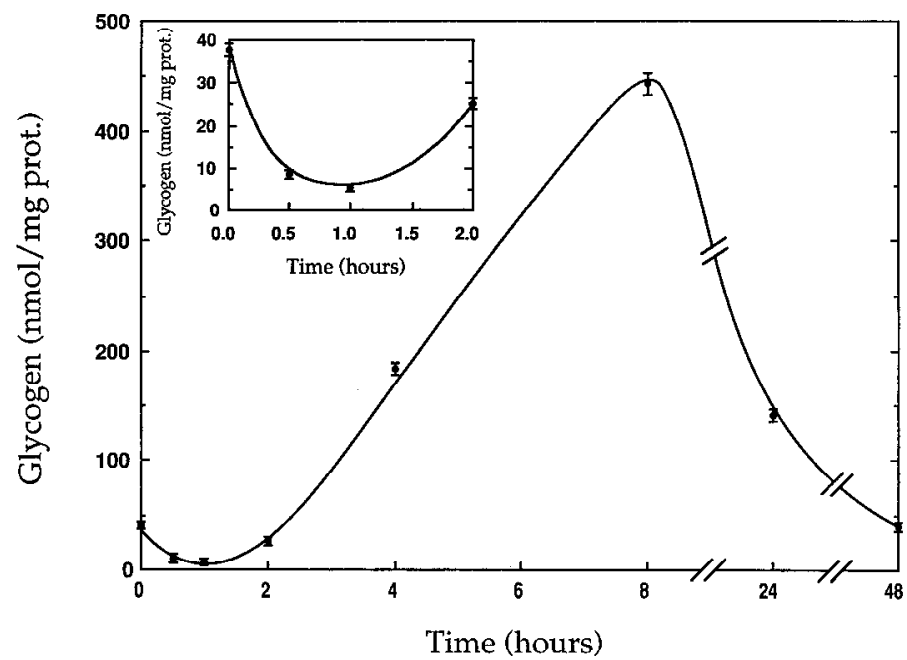

Figure 1. Time course of the effects of VIP on glycogen levels. VIP (1 $\mu \mathrm{M})$ was applied for various periods of time. The inset shows in detail the curve for short periods of VIP application. Results are the mean \pm SEM of quadruplicate determinations from one experiment, repeated once with similar results.

vasoactive intestinal peptide (VIP), exert a potent glycogenolytic action in slices of the cerebral cortex (Magistretti et al., 1981, 1986; Hof et al., 1988). More recently, most of these neurotransmitters have been shown to promote glycogenolysis in primary cultures of astrocytes (Sorg and Magistretti, 1991). In contrast, in this cellularly homogeneous preparation, insulin (Dringen and Hamprecht, 1992), glutamate, and methionine sulfoximine but not phenobarbital (Swanson et al., 1989, 1990) increase in a time- and concentration-dependent manner the glycogen content. These obscrvations led us to propose that the primary action of certain neurotransmitters such as VIP or NA may be to regulate local energy homeostasis within the CNS by acting on non-neuronal cells such as astrocytes (Magistretti, 1990, 1991). From the foregoing set of observations, it is clear that the metabolism of brain glycogen occurs predominantly in astrocytes and that it is more dynamically regulated than previously thought.

As a further indication of the plasticity of brain glycogen metabolism, we report in the present article on a study conducted in primary cultures of mouse cerebral cortical astrocytes, in which two opposed and temporally regulated actions of a single neurotransmitter on glycogen levels are demonstrated. Thus, in addition to promoting glycogenolysis within a few minutes (Sorg and Magistretti, 1991), VIP or NA markedly stimulates the resynthesis of glycogen, resulting in a delayed increase in the glycogen content of astrocyte cultures. This long-term action of VIP or NA is sensitive to protein synthesis inhibition.

\section{Materials and Methods}

Cell culture. Primary cultures of cerebral cortical astrocytes were prepared from Swiss Albino newborn mice (1-2 d old) as previously described (McCarthy and de Vellis, 1980; Sorg and Magistretti, 1991). Briefly, forebrains were removed aseptically from the skulls, the meninges were excised carefully, and the neocortex was dissected. The cells were dissociated by passage through needles of decreasing gauges (1.2 $\times 40 \mathrm{~mm}, 0.8 \times 40 \mathrm{~mm}$, and $0.5 \times 16 \mathrm{~mm}$ ) with a $5 \mathrm{ml}$ syringe. No trypsin was used for dissociation. The cells were seeded at a density of $10^{5} / \mathrm{cm}^{2}$ on six-well plates (Sterilin) in DMEM (Dulbecco's Modified Eagle's Medium) containing $10 \%$ fetal calf serum (FCS), in a final volume of $2 \mathrm{ml}$ per well, and incubated at $37^{\circ} \mathrm{C}$ in an atmosphere containing $5 \% \mathrm{CO}_{2}$ at a $95 \%$ humidity. The culture medium was renewed after 4 $\mathrm{d}$ of seeding and subsequently twice per week. This procedure yields
Table 1. Induction of glycogen resynthesis elicited by VIP as a function of pulse duration

\begin{tabular}{cc} 
Pulse duration & $\begin{array}{c}\text { Glycogen } \\
\text { (nmol/mg }\end{array}$ \\
\hline Experiment 1 & \\
0 & $35 \pm 7$ \\
$10 \mathrm{~min}$ & $149 \pm 18$ \\
$30 \mathrm{~min}$ & $396 \pm 29$ \\
$1 \mathrm{hr}$ & $382 \pm 25$ \\
$2 \mathrm{hr}$ & $381 \pm 13$ \\
$9 \mathrm{hr}$ & $507 \pm 12$
\end{tabular}

Experiment 2

$\begin{array}{cc}0 & 27 \pm 5 \\ 1 \mathrm{~min} & 60 \pm 4 \\ 5 \mathrm{~min} & 69 \pm 4 \\ 15 \mathrm{~min} & 106 \pm 7 \\ 30 \mathrm{~min} & 135 \pm 4 \\ 9 \mathrm{hr} & 365 \pm 16\end{array}$

VIP $(1 \mu \mathrm{M})$ was added for various periods of time. The medium was replaced with one not containing the neurotransmitter, and glycogen levels were assayed $9 \mathrm{hr}$ after the beginning of VIP application. Results are the mean \pm SEM of quadruplicate determinations for each separate experiment.

cultures in which $85-90 \%$ of cells are immunoreactive for glial fibrillary acidic protein (Stoyanov et al., 1988).

Glycogen assay. After 14-21 d in culture, the cells reached confluence and were used for the glycogen assay, as previously described (Sorg and Magistretti, 1991). Culture medium was replaced with a serum-free DMEM containing $5 \mathrm{~mm}$ glucose (instead of $25 \mathrm{~mm}$ for the culture medium). Four hours after having replaced the medium, pharmacological agents were added for various periods of time, during which cultures were maintained in the incubator. The reaction was stopped by washing the cells with ice-cold PBS (phosphate-buffered saline), and by adding $2 \mathrm{ml}$ of $30 \mathrm{~mm} \mathrm{HCl}$. The cells were sonicated and the suspension was used to measure glycogen as described by Nahorski and Rogers (1972). Briefly, three $100 \mu \mathrm{l}$ aliquots were sampled. In the first aliquot, $300 \mu \mathrm{l}$ of acetate buffer were added. In the second, $300 \mu \mathrm{l}$ of a solution containing $10 \%$ of amyloglucosidase $(10 \mathrm{mg} / \mathrm{ml})$ in acetate buffer $(0.1 \mathrm{M}$, pH 4.65) were added, and the mixture was incubated at room temperature for $30 \mathrm{~min}$. After incubation with amyloglucosidase, $2 \mathrm{ml}$ of Tris $\mathrm{HCl}$ buffer $(0.1 \mathrm{M}, \mathrm{pH} 8.1)$ containing $\mathrm{MgCl}_{2}$ (3.3 mM), ATP (0.2 mM), NADP $(25 \mu \mathrm{g} / \mathrm{ml})$, hexokinase $(4 \mu \mathrm{g} / \mathrm{ml})$, and glucose-6-phosphate dehydrogenase $(2 \mu \mathrm{g} / \mathrm{ml})$ were added, and the mixture was incubated at room temperature for $30 \mathrm{~min}$. The first aliquot was treated identically. The fluorescence of the NADPH formed was then read on a fluorometer (excitation, $340 \mathrm{~nm}$; emission, $450 \mathrm{~nm}$ ). The first aliquot gives the sum of glucose and glucose-6-phosphate, while the second gives the sum of glycogen, glucose, and glucose-6-phosphate; the amount of glycogen is then determined by the difference between the first two aliquots. The third aliquot was used to measure the protein content with the method of Bradford (1976). We should note that in this report, 1 mol of glycogen means $1 \mathrm{~mol}$ of glycosyl unit originating from glycogen.

ATP, NADP, and the enzymes were purchased from Boehringer Mannheim; VIP, from Bachem (Bubendorf, Switzerland); and all other reagents, from Sigma Chemical Co. (St. Louis, MO).

Statistical analyses were performed by the Student's $t$ test.

\section{Results}

Application of VIP to primary cultures of mouse astrocytes results in two, time-dependent, effects on glycogen levels. During the first hour of application, the previously described (Sorg and Magistretti, 1991) glycogen hydrolysis is observed, leading to a virtually complete disappearance of glycogen from the cultures (Fig. 1, inset). From $1 \mathrm{hr}$ on, a time-dependent resynthesis of glycogen occurs, resulting, within the third hour of incubation, in glycogen levels similar to those measured prior to the appli- 


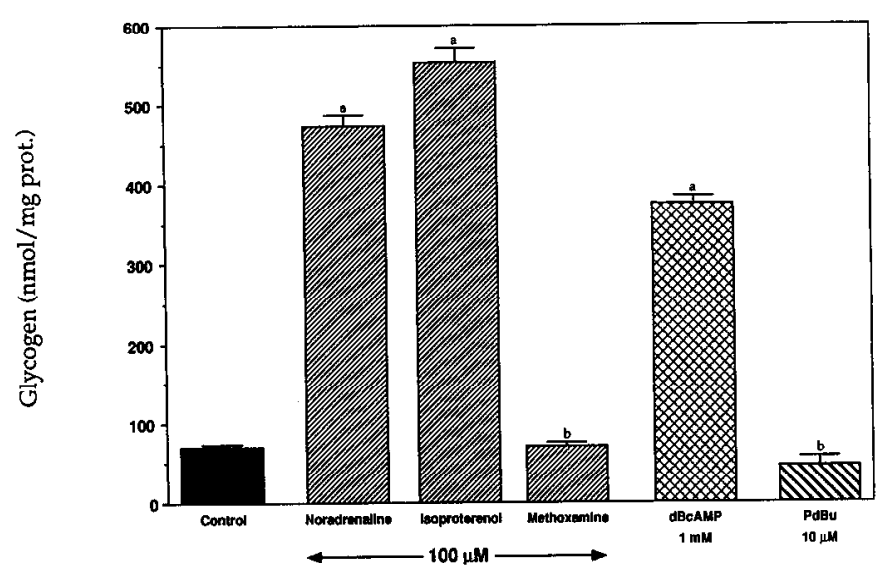

Figure 2. Effect of various glycogenolytic agents on glycogen resynthesis. Agents were applied for 30 min, the medium was replaced with one not containing the agents, and glycogen levels were assayed $8 \mathrm{hr} 30$ min later. Results are the mean \pm SEM of quadruplicate determinations from one experiment, repeated twice for methoxamine and isoproterenol, three times for PdBu, seven times for $\mathrm{dBcAMP}$, and 16 times for NA, with similar results. $a$, glycogen levels significantly different from control $(p<0.01)$; $b$, glycogen levels not significantly different from control $(p>0.01)$.

cation of VIP (Fig. 1). However, most unexpectedly, glycogen levels continue to rise until at least $8 \mathrm{hr}$, reaching levels $6-10$ times higher than those present in the cultures under basal conditions (Fig. 1). This induction of glycogen resynthesis is reversible, since basal levels are reached within $48 \mathrm{hr}$ (Fig. 1).

A puzzling consideration made in light of these results was that the stimulation of glycogen resynthesis could occur despite the continuous presence of a glycogenolytic neurotransmitter such as VIP. This fact led us to wonder whether the sustained exposure of the cultures to VIP was necessary or if a brief application of the peptide could also result in a delayed increase in glycogen levels. To test this possibility, we applied VIP pulses of various duration, changed the medium to remove the peptide, and measured glycogen levels $9 \mathrm{hr}$ after the beginning of the exposure to VIP. As shown in Table 1, pulses of VIP as short as $10 \mathrm{~min}$ resulted, $9 \mathrm{hr}$ later, in glycogen levels four times higher than those obtained under basal conditions. Even a $1 \mathrm{~min}$ pulse could approximately double glycogen levels (Table 1). In view of the foregoing observations, VIP pulses of 10 or $30 \mathrm{~min}$ were used in all further experiments.

At this stage of our analysis, the question was raised of whether the induction of glycogen resynthesis that followed VIP application was simply the consequence of the glycogenolytic action of the peptide or whether glycogenolysis and induction of glycogen synthesis could be dissociated. Results presented in Figure 2 clearly indicate that the latter mechanism occurs. Thus, methoxamine, an $\alpha_{1}$-adrenergic agonist that promotes phosphatidylinositol turnover, and phorbol 12,13-dibutyrate ( $\mathrm{PdBu})$, a direct activator of protein kinase $\mathrm{C}$ (PKC), both promote glycogenolysis without overinducing glycogen synthesis. In contrast, NA and the $\beta$-adrenergic agonist isoproterenol, as well as dibutyryl-cAMP (dBcAMP), that is, threc pharmacological agents that, like VIP, increase cAMP levels in astrocytes and promote a short-term glycogenolysis, all cause a marked overinduction of glycogen synthesis (Fig. 2).

The effect of VIP or NA in stimulating glycogen resynthesis is concentration dependent, becoming significant at concentrations over $100 \mathrm{~nm}$ for both neurotransmitters (Fig. 3).
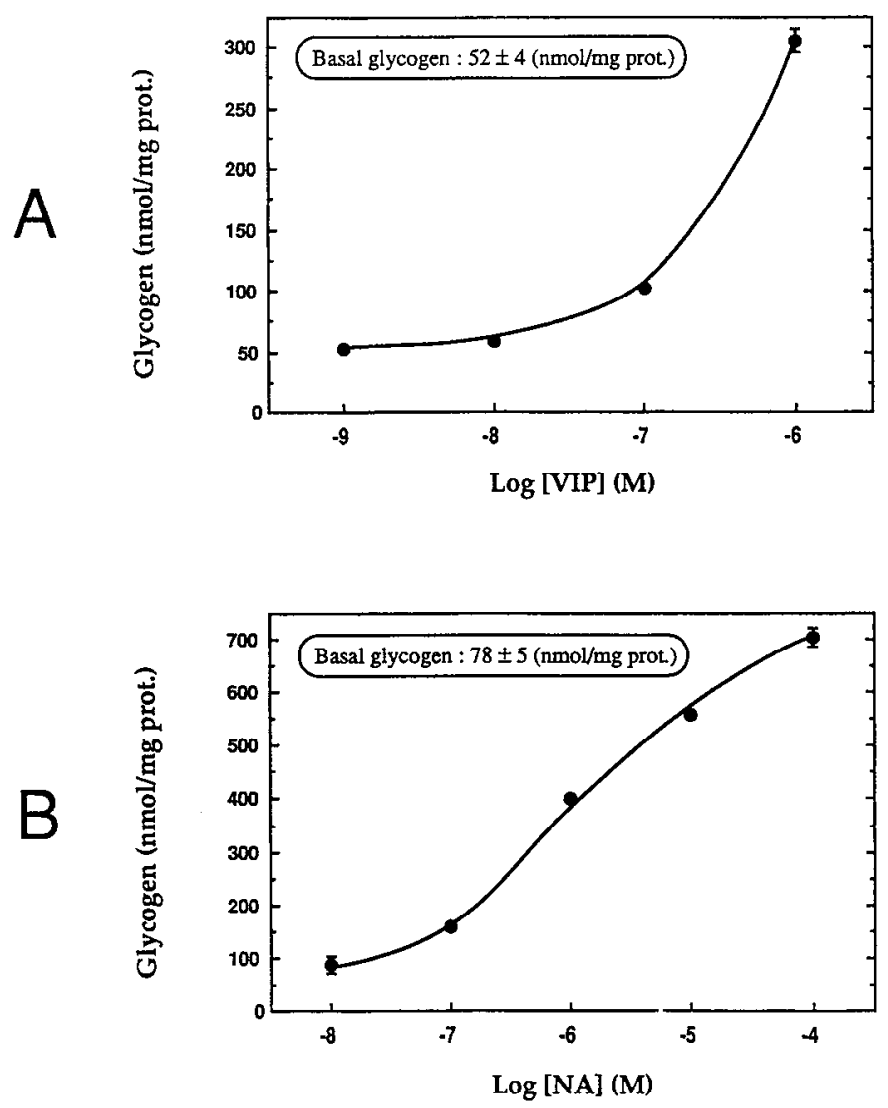

Figure 3. Concentration-response curves of the induction of glycogen resynthesis induced by VIP $(A)$ and NA $(B)$. VIP or NA were applied for $30 \mathrm{~min}$, the medium was replaced with one not containing the neurotransmitters, and glycogen levels were assayed $8 \mathrm{hr} 30 \mathrm{~min}$ later. Results are the mean \pm SEM of quadruplicate determinations from one experiment, repeated once with similar results.

Given the temporally delayed nature of glycogen synthesis overinduction promoted by VIP or NA, we considered the possibility that protein synthesis could be needed to elicit the observed effect. As shown in Figure 4A, this mechanism is likely to be operative, since inhibition of translation by cycloheximide (CX) completely inhibits the VIP- and NA-stimulated glycogen resynthesis. Experiments were carried out as follows: CX (100 $\mu \mathrm{M})$ was applied $1 \mathrm{hr}$ prior to a $30 \mathrm{~min}$ pulse of VIP or NA. After replacing the medium to remove VIP or NA, CX was added again at the same concentration, and glycogen was determined $8 \mathrm{hr}$ and 30 min later. Figure $4 A$ also shows that prolonged (up to $10 \mathrm{hr}$ ) exposure to $\mathrm{CX}$ at $100 \mu \mathrm{M}$ is not toxic to astrocytes, at least as far as glycogen is used as an index, since levels of the polysaccharide in control and CX-treated cultures were not significantly different. However, a consistent observation was a marked decrease in glycogen levels in the cultures exposed to the glycogenolytic neurotransmitters in the presence of CX (Fig. 4A). Inhibition of transcription by actinomycin D at a concentration of $1 \mu \mathrm{M}$ resulted in a similar inhibition of glycogen resynthesis elicited by VIP or NA (not shown).

In view of the known stimulating action of insulin on liver glycogen synthesis and of the previously described presence of insulin receptors functionally coupled to glucose transport in cultured astrocytes (Clarke et al., 1984), we examined the effect of insulin on glycogen levels. As shown in Figure $5 B$, incubation of astrocytes in the presence of insulin for $9 \mathrm{hr}$ results in a 

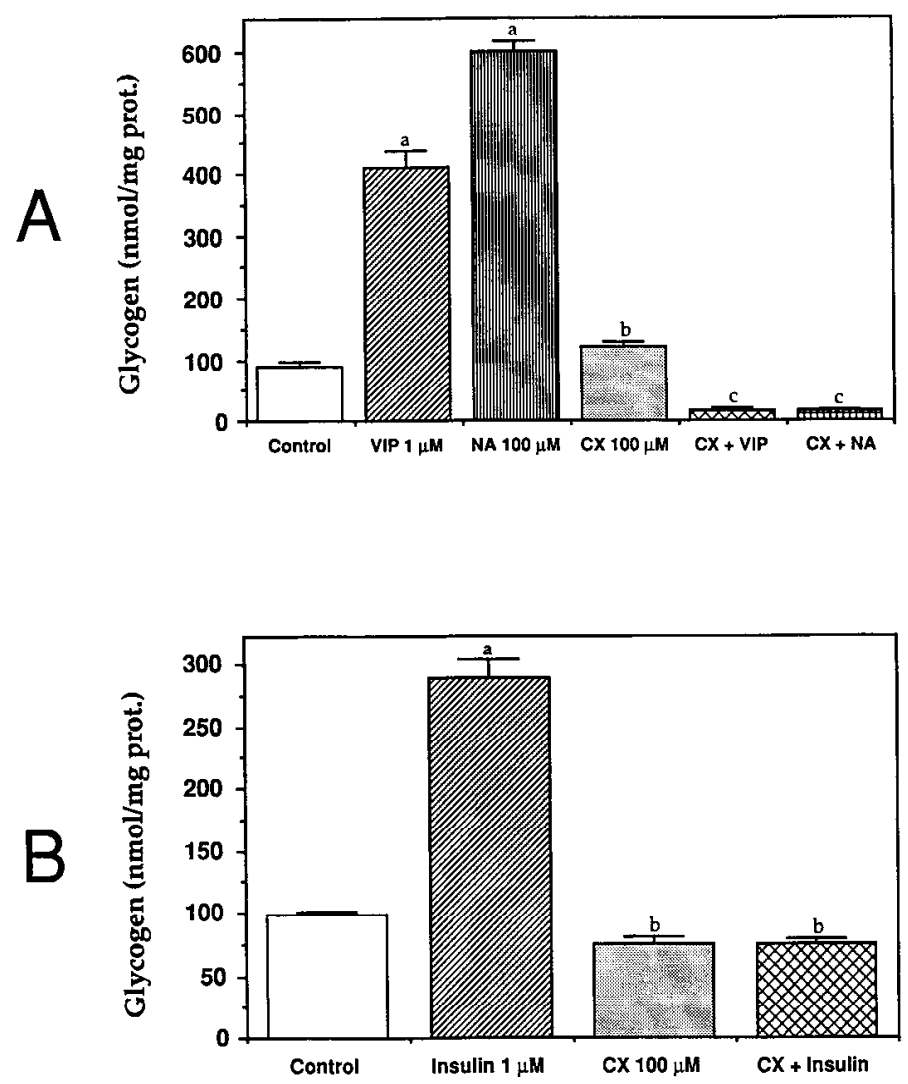

Figure 4. Suppression by cycloheximide (CX) of the induction by VIP $(A)$, NA $(A)$, or insulin $(B)$ of glycogen resynthesis. CX $(100 \mu \mathrm{M})$ was added $1 \mathrm{hr}$ before application of VIP $(1 \mu \mathrm{M})$, NA $(100 \mu \mathrm{M})$, or insulin $(1 \mu \mathrm{M})$; the neurotransmitters and insulin were maintained for $30 \mathrm{~min}$; the medium was then replaced and $C X$ added again; $8 \mathrm{hr} 30 \mathrm{~min}$ later, glycogen levels were assayed. Results are the mean \pm SEM of quadruplicate determinations from one experiment, repeated once with similar results. $a$, glycogen levels significantly higher than control $(p<$ $0.01) ; b$, glycogen levels not significantly different from control $(p>$ $0.01) ; c$, glycogen levels significantly lower than control $(p<0.01)$.

concentration-dependent increase in glycogen levels. The effect is, however, less pronounced than that observed with NA or VIP, since over a number of separate experiments $(n=5)$, glycogen levels reached only two to three times control values, unlike the 6-10-fold increase consistently observed with NA or VIP. The effect of insulin is unidirectional (i.e., no glycogenolysis is elicited) as well as time dependent, with significant increases observed after $2 \mathrm{hr}$ (Fig. 5A). The continuous presence of insulin is not necessary to stimulate glycogen synthesis. Thus, as shown in Figure $4 B$, a 30 min pulse of insulin (1 $\mu \mathrm{M}$ ) can promote glycogen synthesis as measured $8 \mathrm{hr}$ and $30 \mathrm{~min}$ later. As for NA and VIP, the effect of insulin, applied as a 30 min pulse, is abolished by CX (Fig. 4B).

The foregoing observations clearly indicated that glycogen levels could be increased up to 10 -fold by brief exposure to appropriate agents. Since protein synthesis appeared to be involved in this phenomenon, we wondered whether other potential alterations in cell function reflected by the conversion of astrocytes from low- (40-80 nmol/mg protein) versus high- (300$600 \mathrm{nmol} / \mathrm{mg}$ protein) glycogen-containing cells would affect the glycogenolytic action of neurotransmitters. To this end, we examined glycogen hydrolysis elicited by VIP or NA in cultures pretreated for $48 \mathrm{hr}$ with $1 \mathrm{mM}$ dBcAMP, a treatment previously
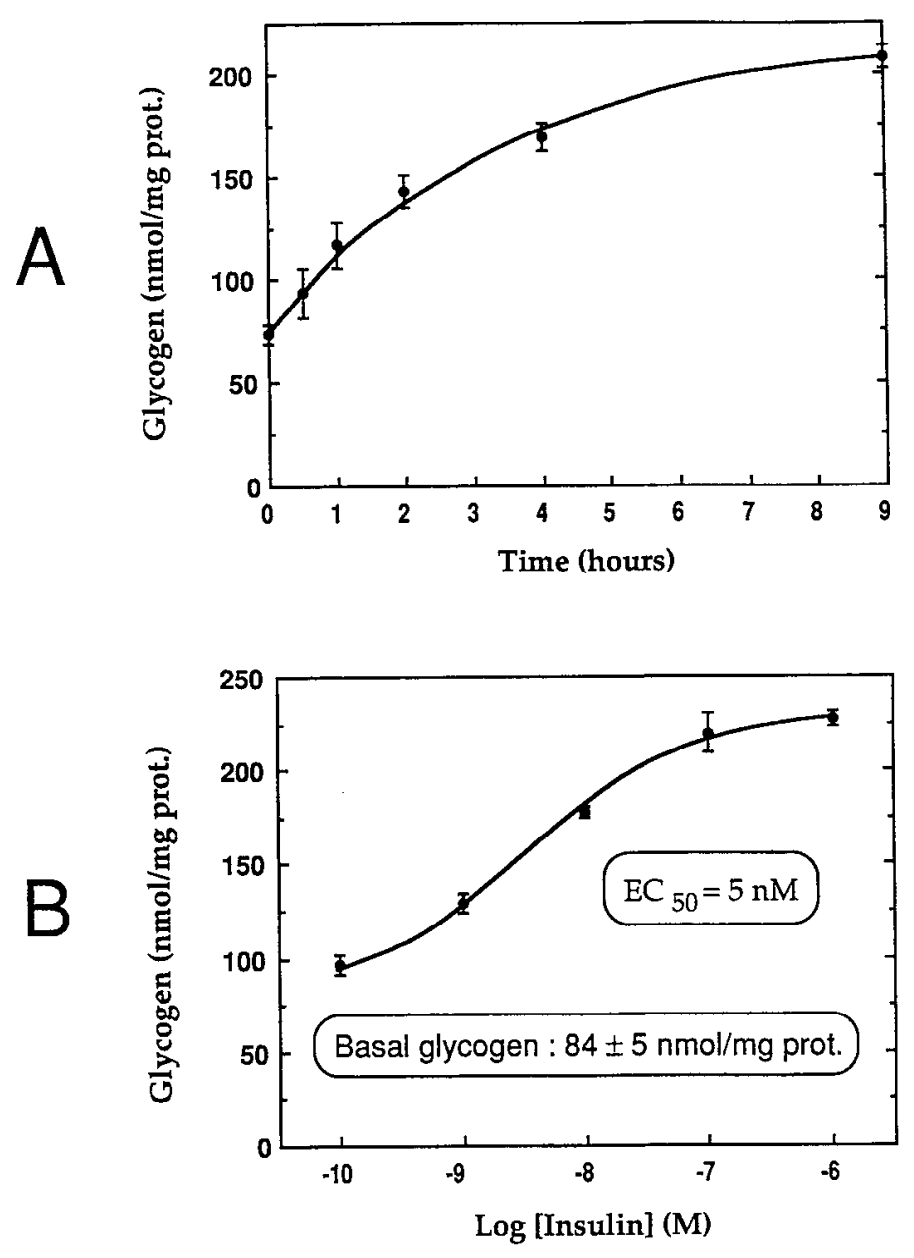

Figure 5. Effect of insulin on glycogen levels. $A$, Time course. Insulin was applied at $1 \mu \mathrm{M}$ for increasing periods of time. $B$, Concentrationresponse curve. Insulin was applied for $9 \mathrm{hr}$ at various concentrations. Results are the mean \pm SEM of quadruplicate determinations from one experiment, repeated twice with similar results. The effect of insulin (1 $\mu \mathrm{M})$ after application for $9 \mathrm{hr}$ was mcasured in four other scparatc experiments.

shown to increase glycogen levels six- to eightfold (Sorg and Magistretti, 1991). As shown in Figure 6, $A$ and $B$, VIP or NA effectively hydrolyzed glycogen with $\mathrm{EC}_{50}$ values of 3 and 50 $\mathrm{nM}$, respectively, which are values very similar, if not identical in the case of VIP, to those previously reported in cultures containing low glycogen levels, that is, around $30 \mathrm{nmol} / \mathrm{mg}$ protein (Sorg and Magistretti, 1991) instead of 284 (Fig. 6A) or 659 (Fig. 6B). A kinetic analysis of VIP- and NA-induced glycogenolysis in high-glycogen containing astrocytes indicates an initial rate of hydrolysis of 8 and $6 \mathrm{nmol} / \mathrm{mg} / \mathrm{min}$ protein, respectively (Fig. $7 A, B$ ), which are values remarkably similar to those observed in low-glycogen-containing cells (Sorg and Magistretti, 1991). However, an important quantitative difference exists between the two conditions: in cultures containing low levels of glycogen, the rate of hydrolysis is linear for 2-5 $\mathrm{min}$, reaches an asymptote within $10 \mathrm{~min}$, and results in $60-80 \mathrm{nmol}$ of glycogen $/ \mathrm{mg}$ protein hydrolyzed over $30 \mathrm{~min}$ (Sorg and Magistretti, 1991). In contrast, in cultures with a high glycogen content, the initial rate of hydrolysis is linear over a 30 min period, resulting in 200-250 nmol of glycogen/mg protein hydrolyzed (Fig. $7 A, B$ ). 

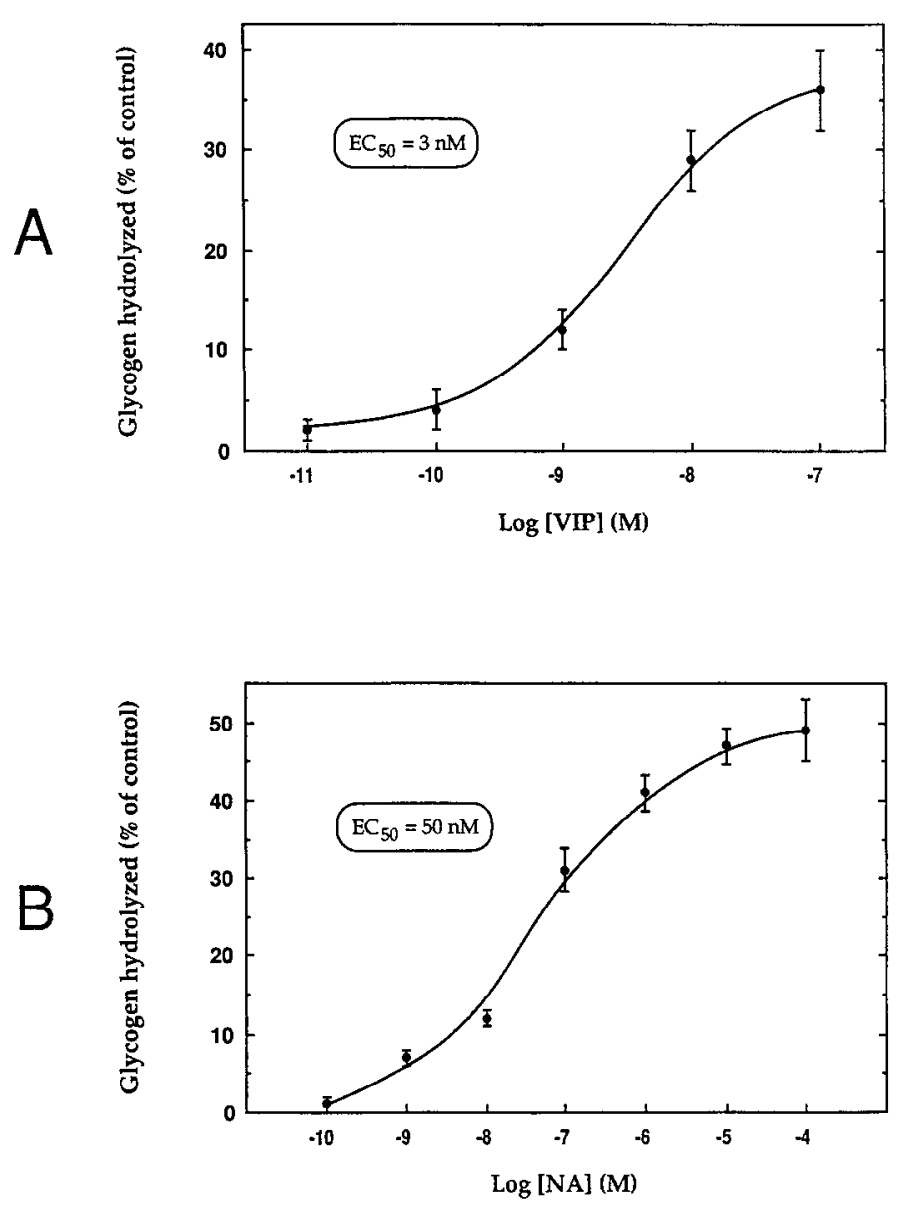

Figure 6. Concentration-response curves of the glycogenolytic effect of VIP $(A)$ and NA $(B)$ after a pretreatment with dBcAMP. Cultures were pretreated for $48 \mathrm{hr}$ with $1 \mathrm{~mm} \mathrm{dBcAMP}$. The day of experiment, the medium was replaced by the standard one ( $5 \mathrm{~mm}$ glucose, no FCS, no dBcAMP); $4 \mathrm{hr}$ later, various concentrations of VIP or NA were applied for $30 \mathrm{~min}$. Basal glycogen levels were $284 \pm 6(A)$ and $659 \pm$ $14(B) \mathrm{nmol} / \mathrm{mg}$ protein for VIP and NA, respectively. Results are the mean \pm SEM of quadruplicate $(A)$ and triplicate $(B)$ determinations from one experiment, repeated twice $(A)$ with similar results.

\section{Discussion}

Results reported in the present study indicate that a given neurotransmitter can exert two opposed effects on glycogen levels in astrocytes. Thus, in addition to their well-documented glycogenolytic action (Sorg and Magistretti, 1991), VIP or NA induce glycogen resynthesis (Fig. 1). This action of VIP or NA occurs after glycogenolysis and can be triggered by brief exposure of the cultures to the neurotransmitters (Table 1). Interestingly, however, the ability of promoting glycogen hydrolysis and glycogen synthesis can be dissociated. Thus, methoxamine, an $\alpha_{1-}$ adrenergic agonist with glycogenolytic properties (Sorg and Magistretti, 1991), does not stimulate glycogen resynthesis (Fig. 2). Similarly, glycogenolysis triggered by $\mathrm{PdBu}$ (Sorg and Magistretti, 1991) is not followed by the induction of glycogen resynthesis (Fig. 2). $\alpha_{1}$-adrenergic receptors are coupled to the phosphatidylinositol cascade that leads to PKC activation, and $\mathrm{PdBu}$ is a direct activator of PKC, while VIP and $\beta$-adrenergic receptors activated by isoproterenol promote cAMP formation (Quik et al., 1978). From the foregoing, it can be concluded that cAMP, and the subsequent activation of protein kinase A (PKA), triggers both glycogenolysis and glycogen resynthesis, while PKC activation is involved only in glycogenolysis. This is also con-
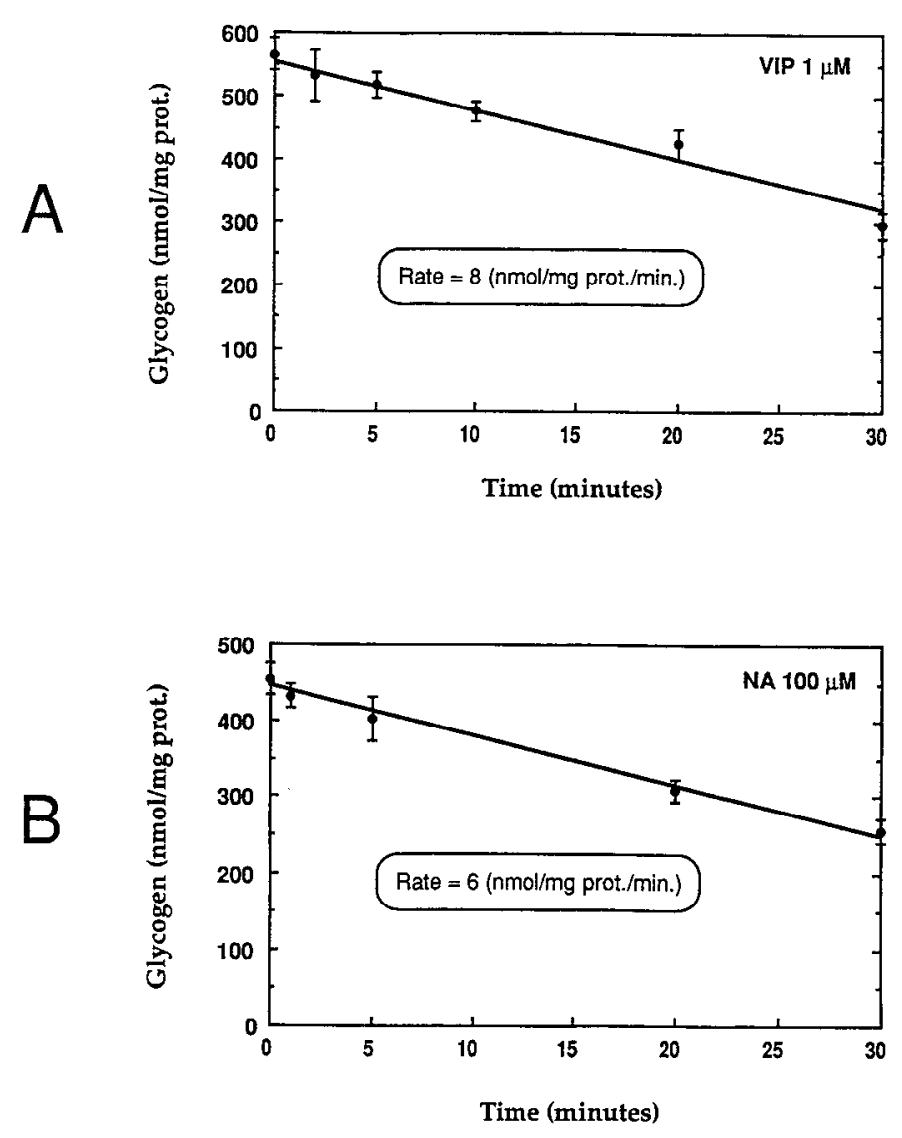

Figure 7. Time course of the glycogenolytic effect of VIP $(A)$ and NA $(B)$ after a pretreatment with $\mathrm{dBcAMP}$. Cultures were pretreated for 48 hr with $1 \mathrm{~mm} \mathrm{dBcAMP}$. The day of experiment, the medium was replaced by the standard one ( $5 \mathrm{~mm}$ glucose, no FCS, no dBcAMP); $4 \mathrm{hr}$ later, $1 \mu \mathrm{M}$ VIP or $100 \mu \mathrm{M}$ NA was applied for various periods of time. Results are the mean \pm SEM of triplicate determinations from one experiment, repeated once with similar results.

firmed by the dual action of dBcAMP, that is, stimulation of glycogen hydrolysis and resynthesis (Fig. 2; Sorg and Magistretti, 1991). A corollary to these comments is that induction of glycogen resynthesis is not the obligatory consequence of glycogenolysis. Furthermore, as illustrated by insulin, induction of glycogen synthesis may also occur without previous glycogen hydrolysis (Fig. 5B). The possible function of insulin in the brain has been long debated. Binding sites have been identified (Roth et al., 1986; Rosenfeld et al., 1987), and in particular functional receptors coupled to increased ${ }^{3} \mathrm{H}$-2-deoxyglucose uptake have been demonstrated in cultured astrocytes (Clarke et al., 1984). Insulin-like immunoreactivity has been detected in the brain (Baskin et al., 1987; Wood et al., 1989), and an increase in glycogen levels, following insulin application in vitro to olfactory bulb slices, has been demonstrated (Coopersmith and Leon, 1987). Furthermore, a recent report has indicated a stimulatory effect of insulin on glycogen synthesis in astrocyte cultures (Dringen and Hamprecht, 1992), in a manner very similar to the observations reported here. Thus, a near doubling in glycogen levels was observed within $2 \mathrm{hr}$ of insulin application, with an $\mathrm{EC}_{50}$ in the low nanomolar range (Fig. 5A,B; Dringen and Hamprecht, 1992). In contrast to the present report, however, the effect of insulin was revealed in cultures that had been starved of glucose for $2 \mathrm{hr}$, a treatment that decreased intracellular glycogen content by approximately $80 \%$ of normal levels (Dringen 
and Hamprecht, 1992). In our study, we demonstrate that the effect of insulin is expressed in the presence of physiological concentrations of glucose. Furthermore, we have observed that a 30 min pulse of insulin is sufficient to promote glycogen synthesis through a mechanism that is sensitive to protein synthesis inhibition (Fig. 4B). Taken together, results reported here and in previous studies further stress the metabolic role played by insulin, or by insulin-like molecules, within the nervous system.

The effect of VIP, NA and also of insulin in increasing glycogen levels is observed, with a temporal delay, even after a brief application to the cultures. Thus, it is striking to note that a 1 min pulse of VIP leads to the doubling of glycogen levels within $9 \mathrm{hr}$ after application. This observation strongly indicates that a cascade of events is triggered by the neurotransmitter, which progresses independent of receptor occupation. A likely step in this cascade of events is the increase in cAMP levels. Experiments in our laboratory indicate that following VIP application to astrocyte cultures, cAMP levels peak at $10 \mathrm{~min}$ and return to basal levels within $1 \mathrm{hr}$ (P. J. Magistretti, M. Maillard, and J. L. Martin, unpublished observations). Evidence has been provided in recent years indicating that PKA can phosphorylate, among a number of substrates, a transcription factor called CREB (cAMP-responsive element-binding protein), which acts on specific DNA sequences, that is, cAMP-responsive elements, to regulate the expression of certain genes (Yamamoto et al., 1988; Montminy et al., 1990; Sheng et al., 1990). A clear example is the regulation by cAMP of the gene encoding for somatostatin (Gonzalez and Montminy, 1989) and for a number of G-protein-coupled membrane receptors, such as the substance $\mathrm{P}$ or the $\beta$-adrenergic receptors (Hershey et al., 1991; Collins et al., 1992). The fact that the increase in glycogen levels elicited by VIP or NA, two neurotransmitters that promote cAMP formation in astrocytes, is temporally delayed and sensitive to agents that inhibit DNA transcription and RNA translation strongly suggests that the synthesis of one or more enzymes involved in glycogen anabolism might be the molecular mechanism underlying the effect of VIP and NA. A number of enzymes are potential candidates for such regulation. Thus, glycogen synthase transcription could be enhanced by VIP or NA. Furthermore, since the activity of glycogen synthase is decreased, while that of phosphorylase is enhanced by phosphorylation, induction by VIP or NA of mRNA transcripts for phosphatases and their subsequent translation can also be envisioned. The dephosphorylation of glycogen synthase and phosphorylase that would result from increased phosphatase activity would favor glycogen synthesis. As to the effect of insulin, the synthesis of a number of mRNAs has been shown to be enhanced by the peptide in peripheral tissues, although the cascade of intracellular events leading to such effects is still largely unknown (Sasaki et al., 1984).

To begin to tackle the functional significance of increased glycogen content in astrocytes, the glycogenolytic effect of VIP or NA in cultures in which glycogen levels had been increased four- to sixfold by treatment with dBcAMP was examined. Analysis of the time and concentration dependence of the glycogenolytic action exerted by VIP or NA under those conditions clearly indicates that the potency of both neurotransmitters, as well as the rate/minute of glycogen hydrolysis, is virtually identical in astrocytes with low (Sorg and Magistretti, 1991) and high (Figs. $6 A, B ; 7 A, B$ ) glycogen content; however, the initial rate is maintained for at least $30 \mathrm{~min}$ in glycogen-rich astrocytes, indicating that considerably more glycosyl units are released.
As a comparison, in astrocytes containing low glycogen levels, 30-80 nmoles of glycogen per $\mathrm{mg}$ of protein are hydrolyzed within the first $30 \mathrm{~min}$ after VIP or NA application, while in glycogen-rich astrocytes this value ranges between 200 and 250 (Fig. $7 A, B$ ). The question can therefore be raised of which of the two types of cultures reflects more closely in vivo conditions. The glycogen content of whole rodent brain ranges between 20 and $60 \mathrm{nmol} / \mathrm{mg}$ protein (Passonneau and Lauderdale, 1974; Sagar et al., 1987); a recent report in which microwave irradiation was used as an improved inactivation procedure indicated glycogen levels of $33 \mathrm{nmol} / \mathrm{mg}$ protein in rat cerebral cortex (Sagar et al., 1987). Under the experimental conditions used in this study, the mean glycogen content of primary astrocyte cultures was $62 \pm 8(n=60)$, a value in good agreement with other recent reports (Swanson et al., 1989, 1990; Dringen and Hamprecht, 1992). When expressing the results of glycogen content in vivo per milligram of protein, one should bear in mind that glycogen is predominantly contained in astrocytes (Sotelo and Palay, 1968; Vaughn and Grieshaber, 1972), while other cells, namely neurons, which contain virtually no glycogen, contribute to the measured proteins. This means that in vivo studies underestimate the glycogen content of astrocytes, the question being by what factor. Since astrocytes constitute approximately half of the volume of the cerebral cortex (Kimelberg and Norenberg, 1989; Bignami, 1991; Peters et al., 1991), one could roughly estimate that glycogen content of astrocytes in vivo to be about $50-60 \mathrm{nmol} / \mathrm{mg}$ protein, that is, twice the value obtained when expressing the results by taking into account the protein content of cells that contain virtually no glycogen. An even more conservative estimate can be made by considering the fact that astrocytes outnumber neurons in the gray matter by approximately a factor of 10 (Bignami, 1991; Peters et al., 1991). This would indicate that levels of glycogen measured in vivo and expressed per milligram of protein should be corrected by only $10 \%$ to estimate astrocytic glycogen in vivo. Regardless of the correction factor used, it is clear that glycogen levels measured in the cultures after induction by VIP or NA, that is, values ranging between 250 and $600 \mathrm{nmol} / \mathrm{mg}$ protein, are considerably higher than those estimated in vivo.

What is, then, the significance of the induction of high glycogen levels by VIP or NA? One consideration that can be made is that astrocytes present in the cultures have not been exposed to neurotransmitters for 2-3 weeks, in contrast to their in vivo counterparts. Application of VIP or NA to neurotransmitternaive astrocytes could therefore trigger the expression of developmentally regulated processes that result in glycogen levels normally found in the fully differentiated astrocytes present in vivo. However, as discussed earlier, the levels of glycogen in vivo are similar, after appropriate correction, to those observed in neurotransmitter-naive cultures rather than to those measured in cultures treated with VIP or NA. These considerations would therefore tend to discard the possibility that neurotransmitternaive astrocytes are brought, by the exposure to VIP or NA, to a state of differentiation that results in glycogen levels observed in vivo. An obvious difference between the situation in vivo and in primary astrocyte cultures is that in the latter condition, neurons are missing. It is therefore likely that a subtle interplay between the glycogenolytic and synthetic effects of VIP or NA released in vivo, according to precise spatial and temporal modalities, results in levels of glycogen dynamically equilibrated around $30 \mathrm{nmol} / \mathrm{mg}$ of protein, that is, levels that are similar to those measured in unstimulated astrocytes in vitro. It is also 
likely that other neuronally generated signals contribute to the stabilization of glycogen to the levels encountered in vivo. However, when astrocytes are exposed in vitro to VIP or NA in the absence of neurons, the full potential of the glycogen-synthetic effect of the two neurotransmitters is expressed undisturbed to yield glycogen levels in the hundreds of nmoles per milligram of protein. Slowly, however, that is, within $48 \mathrm{hr}$, the glycogen content of astrocytes returns to basal levels (Fig. 1).

These considerations may have a bearing to the increased glycogen content that is frequently encountered in certain types of reactive astrocytes, in particular following traumatic lesions of the brain parenchyma (Shimizu and Hamuro, 1958; Hager et al., 1967; Haymaker et al., 1970; Watanabc and Passonncau, 1974; Al-Ali and Robinson, 1982) and $\alpha$-particle or x-irradiation (Wolfe et al., 1962; Lundgren and Miquel, 1970). Under these conditions, astrocytes, notably those that surround the lesioned area where neuronal death has occurred, are enriched in glycogen as assessed biochemically (Watanabe and Passonneau, 1974) and visualized by light and electron microscopy (Hager et al., 1967; Al-Ali and Robinson, 1982). The time course of the changes in glycogen levels has been examined following stab wounds in rat cerebral cortex (Watanabe and Passonneau, 1974). Within few minutes after the lesion, the glycogen content is markedly decreased. Concomitantly, cAMP levels reach peak values that are sevenfold higher than the control, returning to basal levels within $1 \mathrm{hr}$. In contrast, glycogen accumulation follows the initial decrease, reaching, already at $2.5 \mathrm{hr}$, values that are 2.5-fold higher than control levels (Watanabe and Passonneau, 1974). This increase in glycogen content in the vicinity of the lesion is maintained for at least $24 \mathrm{hr}$. The temporal pattern of glycogen decrease followed by increased glycogen deposition is strikingly similar to results reported in this article. Another study has indicated that localized lesions of the cerebral cortex caused by needle penetration result in an increase in glycogen levels not only at the site of reactive gliosis surrounding the insult, but also at distant sites throughout the neocortical mantle (Haymaker et al., 1970). Marked glycogen increases are also observed following inhibition of synaptic transmission by general anesthetics, that is, another condition in which neuronally generated signals to astrocytes are likely to be decreased (Nelson et al., 1968; Brunner et al., 1971; Passonneau et al., 1971). Recently, blockade of action potentials in the afferent nerve has been shown to produce reactive astrocytes in the chick cochlear nucleus (Canady and Rubel, 1992). It would be of intcrest to determine whether these reactive astrocytes also contain high glycogen levels.

The role of astrocytic glycogen in neural function has not yet been fully clarified. As noted earlier, the decrease in neuronal activity caused by lesions or by general anesthesia, markedly increases the glycogen content of astrocytes, indicating that under conditions of physiological synaptic activity, the turnover of the polysaccharide is rapid. In line with this view is the presence of corpora amylacea, that is, spherical bodies of 10 $15 \mu \mathrm{m}$ diameter revealed by standard glycogen stains, that are found in fibrous astrocytes of normal aging brains and in certain neurodegenerative disorders (Hume Adams et al., 1984). Like other cytoplasmic inclusions collectively denominated polyglucosan bodies (Robitaille et al., 1980; Thomas et al., 1980), such as Lafora and Bielschowsky bodies or amylopectin bodies of type IV glycogenosis, corpora amylacea are constituted by glucose polymers, implying that they are similar, if not identical, to glycogen. The mechanisms that lead to the accumulation of

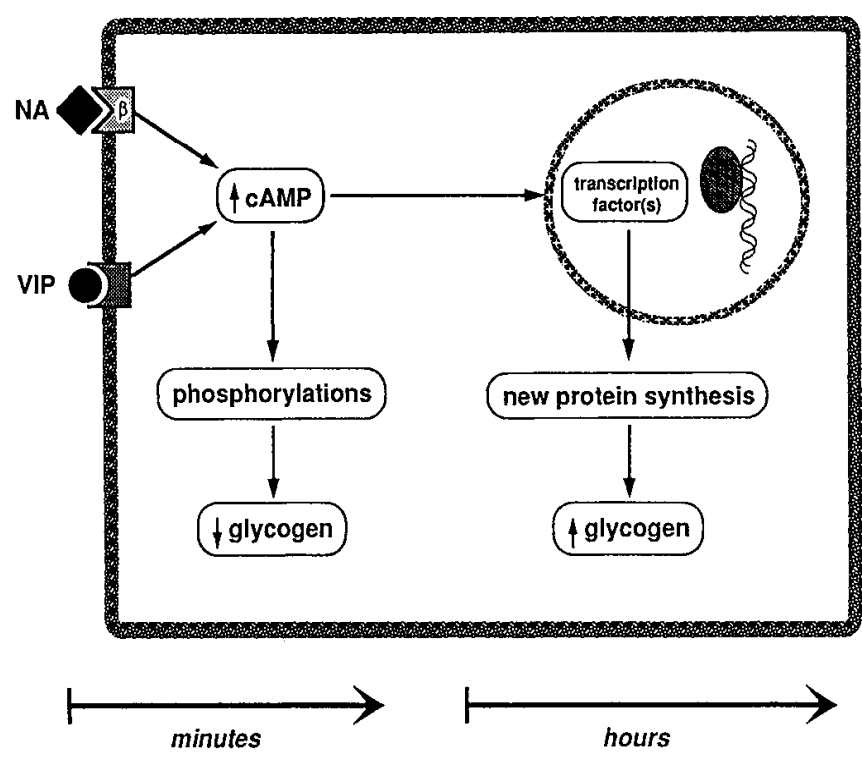

Figure 8. Bidirectional effects of VIP or NA on glycogen in astrocytes. With the short-term effect, within minutes after application, VIP or NA promote glycogenolysis. This effect is due to cAMP-dependent phosphorylation of preexisting proteins. With the long-term effect, within a few hours after application of VIP or NA, glycogen levels are increased 6-10 times above control levels. This effect is due to cAMP-dependent induction of new protein synthesis.

such glycogen-containing inclusions in astrocytes are unknown. It is conceivable that in pathological situations in which neuronal activity is decreased, glucose supplied by the circulation is in considerable excess of either the capacity of astrocytes to hydrolyze glycogen under the action of neurotransmitters such as VIP and NA, or of the energy requirements of the brain parenchyma. Supporting this view is the observation of increased glycogen deposition in cortical astrocytes of patients afflicted by Alzheimer's disease (Mann ct al., 1987), a condition in which a considerable loss of neurons is at the forefront of the histopathological diagnosis (Hume Adams et al., 1984).

As previously reviewed, it is clear that glycogen represents an energy substrate reserve under the tight control of various neurotransmitters, including VIP and NA (Magistretti, 1990). In passing, one can note that the initial velocity of the glycogenolysis elicited by VIP or NA, that is, $7-9 \mathrm{nmol} / \mathrm{mg}$ protein $/ \mathrm{min}$ (Sorg and Magistretti, 1991), is of the same order of magnitude as the glucose utilization of the rodent cerebral cortex measured with the 2-deoxyglucose technique, that is, $10-16 \mathrm{nmol} / \mathrm{mg}$ protein $/$ min (Sokoloff et al., 1989). This correlation would tend to indicate that glycogen hydrolysis evoked by neurotransmitters may provide, in a quantitatively significant manner, energy substrates for neuronal function.

Regardless of the possible implications in brain pathophysiology, results reported in this study clearly indicate that the two neurotransmitters VIP and NA exert actions on glycogen metabolism, which, while appearing opposite in nature at superficial analysis, may in fact be endowed with a functional and teleologically directed complementarity. Thus, by increasing cAMP levels, VIP or NA simultaneously trigger a short-term effect, that is, glycogenolysis, as well a delayed one, that is, transcriptionally regulated glycogen resynthesis. This longer-term effect ensures that sufficient substrate is available for the continued expression of the short-term action of VIP or NA (Fig. 8). 


\section{References}

Al-Ali SY, Robinson N (1982) Ultrastructural study of enzymes in reactive astrocytes: clarification of astrocytic activity. Histochem $\mathbf{J}$ $14: 311-321$.

Baskin DG, Figlewicz DP, Woods SC, Porte D, Dorsa DM (1987) Insulin in the brain. Annu Rev Physiol 49:335-347.

Bignami A (1991) Discussions in neuroscience, Vol VIII, No 1, Glial cells in the central nervous system. Amsterdam: Elsevier.

Bradford MM (1976) A rapid and sensitive method for the quantitation of microgram quantities of protein using the principle of protein-dye binding. Ann Biochem 72:248-254.

Brunner EA, Passonneau JV, Molstad C (1971) The effect of volatile anaesthetics on levels of metabolites and on metabolic rate in brain. J Neurochem 18:2301-2316.

Canady KS, Rubel EW (1992) Rapid and reversible astrocytic reaction to afferent activity blockade in chick cochlear nucleus. J Neurosci 12 : 1001-1009.

Clarke DW, Boyd FT Jr, Kappy MS, Raizada MK (1984) Insulin binds to specific receptors and stimulates 2-deoxy-D-glucose uptake in cultured glial cells from rat brain. J Biol Chem 259:11672-11675.

Collins S, Caron MG, Lefkowitz RJ (1992) From ligand binding to gene expression: new insights into the regulation of $G$-protein coupled receptors. Trends Biochem Sci 17:37-39.

Coopersmith R, Leon M (1987) Carnosine and insulin increase olfactory bulb glycogen synthesis. Soc Neurosci Abstr 13:1483.

Dringen R, Hamprecht B (1992) Glucose, insulin and insulin-like growth factor I regulate the glycogen content of astroglia-rich primary cultures. J Neurochem 58:511-517.

Gonzalez GA, Montminy MR (1989) Cyclic AMP stimulates somatostatin gene transcription by phosphorylation of CREB at serine 133. Cell 59:675-680.

Hager H, Luh S, Ruscáková D, Ruscák M (1967) Histochemische, elekronmikroscopische und biochemische Untersuchungen über Glykogenanhäufung in reaktiv veränderten Astrozyten der traumatisch lädierten Säugergrobhirnrinde. Z Zellforsch Mikrosk Anat 83:295320.

Haymaker W, Miquel J, Ibrahim MZH (1970) Glycogen accumulation following brain trauma. Bibl Psychiatr 10:71-87.

Hershey AD, Dykema PE, Krause JE (1991) Organization, structure, and expression of the gene encoding the substance $P$ receptor. $J$ Biol Chem 266:4366-4374.

Hof PR, Pascale E, Magistretti PJ (1988) $\mathrm{K}^{+}$at concentrations reached in the extracellular space during neuronal activity promotes a $\mathrm{Ca}^{2+}-$ dependent glycogen hydrolysis in mouse cerebral cortex. J Neurosci 8:1922-1928.

Hume Adams J, Corsellis JAN, Duchen LW (1984) Greenfield's neuropathology. New York: Wiley.

Ibrahim MZ (1975) Glycogen and its related enzymes of metabolism in the central nervous system. Adv Anat Embryol Cell Biol 52:3-89.

Karnovsky ML, Reich P, Anchors JM, Burrows BL (1983) Changes in brain glycogen during slow-wave sleep in the rat. J Neurochem 41: 1498-1501.

Kimelberg HK, Norenberg MD (1989) Astrocytes. Sci Am 260:4452.

Lundgren PR, Miquel J (1970) The incorporation of isotopic carbon ${ }^{14} \mathrm{C}$ into the cerebral glycogen of normal and $\mathrm{X}$-irradiated rats. $\mathrm{J}$ Neurochem 17:1383-1386.

Magistretti PJ (1988) Regulation of glycogenolysis by neurotransmitters in the central nervous system. Diab Metab (Paris) 14:237-246.

Magistretti PJ (1990) VIP neurons in the cerebral cortex. Trends Pharmacol Sci 11:250-254.

Magistretti PJ (1991) Actions of neurotransmitters on non-neuronal cells as evidence for the existence of intrinsic neuronal circuits controlling local energy metabolism and cellular homeostasis within the central nervous system. In: Alfred Benzon symposium 31, Brain work and mental activity (Lassen NA, Ingvar DH, Raichle ME, Friberg L, eds), pp 94-107. Copenhagen: Munksgaard.

Magistretti PJ, Morrison JH, Shoemaker WJ, Sapin V, Bloom FE (1981) Vasoactive intestinal polypeptide induces glycogenolysis in mouse cortical slices: a possible regulatory mechanism for the local control of energy metabolism. Proc Natl Acad Sci USA 78:6535-6539.

Magistretti PJ, Hof PR, Martin JL (1986) Adenosine stimulates glycogenolysis in mouse cerebral cortex: a possible coupling mechanism between neuronal activity and energy metabolism. J Neurosci 6:25582562.

Mann DMA, Sumpter PQ, Davies CA, Yates PO (1987) Glycogen accumulations in the cerebral cortex in Alzheimer's disease. Acta Neuropathol (Berl) 73:181-184.

McCarthy KD, de Vellis J (1980) Preparation of separate astroglial and oligodendroglial cell cultures from rat cerebral tissue. J Cell Biol 85:890-902.

Montminy MR, Gonzalez GA, Yamamoto KK (1990) Regulation of cAMP-inducible genes by CREB. Trends Neurosci 13:184-188.

Nahorski SR, Rogers KJ (1972) An enzymatic fluorometric micromethod for determination of glycogen. Anal Biochem 49:492-497.

Nelson SR, Schulz DW, Passonneau JV, Lowry OH (1968) Control of glycogen levels in brain. J Neurochem 15:1271-1279.

Passonneau JV, Lauderdale VR (1974) A comparison of three methods of glycogen measurement in tissues. Anal Biochem 60:405-412.

Passonneau JV, Brunner EA, Molstad C, Passonneau R (1971) The effects of altered endocrine states and ether anesthesia on mouse brain. J Neurochem 18:2317-2328.

Peters A, Palay SL, Webster HF (1991) The fine structure of the nervous system; neurons and their supporting cells. Philadelphia: Saunders.

Phelps CH (1972) Barbiturate-induced glycogen accumulation in brain. An electron microscopic study. Brain Res 39:225-234.

Phclps CH (1975) An ultrastructural study of methionine sulfoximineinduced glycogen accumulation in astrocytes of the mouse cerebral cortex. J Neurocytol 4:479-490.

Quach TT, Rose C, Schwartz JC (1978) [ $\left.{ }^{3} \mathrm{H}\right]$ glycogen hydrolysis in brain slices: responses to neurotransmitters and modulation of noradrenaline receptors. J Neurochem 30:1335-1341.

Quach TT, Duchemin AM, Rose C, Schwartz JC (1980) [ [ ${ }^{3} \mathrm{H} \mid \mathrm{glycogen}$ hydrolysis elicited by histamine in mouse brain slices: selective involvement of $\mathrm{H}_{1}$-receptors. Mol Pharmacol 20:331-338.

Quach TT, Rose C, Duchemin AM, Schwartz JC (1982) Glycogenolysis induced by serotonin in brain: identification of a new class of receptors. Nature 298:373-375.

Quik M, Iversen LL, Bloom, SR (1978) Effect of vasoactive intestinal peptide (VIP) and other peptides on cAMP accumulation in rat brain. Biochem Pharmacol 27:2209-2213.

Robitaille Y, Carpenter S, Karpati G, Di Mauro S (1980) A distinct form of adult polyglucosan body disease with massive involvement of central and peripheral neuronal processes and astrocytes. A report of four cases and a review of the occurrence of polyglucosan bodies in other conditions such as Lafora's disease and normal aging. Brain 103:315-336.

Rosenfeld RG, Pham H, Keller BT, Bochardt RT, Pardridge WM (1987) Demonstration and structural comparison of receptors for insulinlike growth factor-I and -II (IGF-I and IGF-II) in brain and bloodbrain barrier. Biochem Biophys Res Commun 149:59-166.

Roth RA, Morgan DO, Beaudoin J, Sara V (1986) Purification and characterization of the human brain insulin receptor. J Biol Chem 261:3753-3757.

Sagar SM, Sharp FR, Swanson RA (1987) The regional distribution of glycogen in rat brain fixed by microwave irradiation. Brain Res 417:172-174.

Sasaki K, Cripe TP, Koch SR, Andreone TL, Petersen DD, Beale EG, Granner DK (1984) Multihormonal regulation of phosphoenolpyruvate carboxykinase gene transcription. J Biol Chem 259:1524215251 .

Sheng M, McFadden G, Greenberg ME (1990) Membrane depolarization and calcium induce c-fos transcription via phosphorylation of transcription factor CREB. Neuron 4:571-582.

Shimizu N, Hamuro Y (1958) Deposition of glycogen and changes in some enzymes in brain wounds. Nature 181:781-782.

Siesjö BK (1978) Brain energy metabolism. New York: Wiley.

Sokoloff L, Kennedy C, Smith CB (1989) The $\left[{ }^{14} \mathrm{C}\right]$ deoxyglucose method for measurement of local cerebral glucose utilization. In: Ncuromethods, Vol 11, Carbohydrates and energy metabolism (Boulton AA, Baker GB, Butterworth RF, eds), pp 155-193. Clifton, NJ: Humana.

Sorg O, Magistretti PJ (1991) Characterization of the glycogenolysis elicited by vasoactive intestinal peptide, noradrenaline and adenosine in primary cultures of mouse cerebral cortical astrocytes. Brain Res 563:227-233. 
Sotelo C, Palay SL (1968) The fine structure of the lateral vestibular nuclcus in the rat. I. Ncurons and ncuroglial cells. J Cell Biol 36:151179.

Stoyanov T, Martin JL, Magistretti PJ (1988) VIP binding sites in primary cultures of astrocytes. Eur J Neurosci [Suppl] 1:111.

Swanson RA, Yu ACH, Sharp FR, Chan PH (1989) Regulation of glycogen content in primary astrocyte culture: effect of glucose analogues, phenobarbital, and methionine sulfoximine. J Neurochem 52 $1359-1365$.

Swanson RA, Yu ACH, Chan PH, Sharp FR (1990) Glutamate increases glycogen content and reduces glucose utilization in primary astrocyte culture. J Neurochem 54:490-496.

Thomas PK, King RHM, Sharma AK (1980) Changes with age in the peripheral nerves of the rat. An ultrastructural study. Acta Neuropathol (Berl) 52:1-6.

Vaughn JE, Grieshaber JA (1972) An electron microscopic investigation of glycogen and mitochondria in developing and adult rat spinal motor neuropil. J Neurocytol 1:397-412.
Watanabe H, Passonneau JV (1973) Factors affecting the turnover of cerebral glycogen and limit dextrin in vivo. J Neurochem 20:15431554.

Watanabe H, Passonneau JV (1974) The effect of trauma on cerebral glycogen and related metabolites and enzymes. Brain Res 66:147159.

Wolfe LS, Klatzo I, Miquel J, Tobias C, Haymaker W (1962) Effect of alpha-particle irradiation on brain glycogen in the rat. J Neurochem 9:213-218.

Wood TL, Berelowitz M, McKelvy JF (1989) Hormonal feedback regulation of brain IGF-I and IGF-II gene expression. In: Molecular and cellular biology of insulin-like growth factors and their receptors (LeRoith D, Raizada MK, eds), pp 209-217. New York: Plenum.

Yamamoto KK, Gonzalez GA, Biggs WH III, Montminy MR (1988) Phosphorylation-induced binding and transcriptional efficacy of nuclear factor CREB. Nature 334:494-498. 